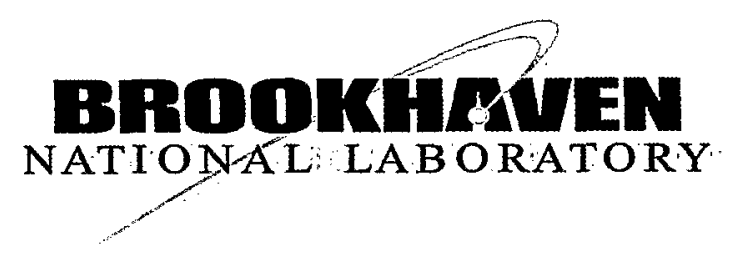

BNL $-74726-2005-C P$

\title{
CdTe Ceramics Based on Compression of Nanocrystal Powder
}

N.N. Kolesnikov, E.B. Borisenko, D.N. Borisenko, R.B. James, V.V. Kveder, V.K. Gartman, B.A. Gnesin

Presented at the 2005 SPIE Optics and Photonics:

San Diego, California

July 31 - August 4, 2005

May 2005

Associate Laboratory Director

Energy, Environment and National Security Directorate

\author{
Brookhaven National Laboratory \\ P.O. Box 5000 \\ Upton, NY 11973-5000: \\ www.bnl.gov:
}

Managed by

Brookhaven Science Associates, LLC

for the United States Department of:Energy under.

Contract No.:DE-AC02-98CH10886

This is a preprint of a paper intended for publication in a journal or proceedings. Since changes may be made before publication, this preprint is made available with the understanding that it will not be cited or reproduced without the permission of the author. 


\section{DISCLAIMER}

This report was prepared as an account of work sponsored by an agency of the United States Government: Neither the United States Government nor any agency thereof, nor any of their employees, nor any of their contractors, subcontractors; ' or their employees, makes any warranty; express or implied, or assumes any legal liability or responsibility for the accuracy, completeness, or any third party's use or the results of such use of any information, apparatus, product, or process disclosed, or represents that its use would not infringe privately owned rights. Reference herein to any specific commercial product, process, or service: by trade name; trademark; manufacturer; or otherwise, does not necessarily: constitute or imply its endorsement, recommendation, or favoring by the United States Government or any agency thereof or its contractors or subcontractors. The views and opinions of authors expressed herein do not necessarily state or reflect those of the United States Government or any agency thereof. 


\title{
CdTe Ceramics Based on Compression of Nanocrystal Powder
}

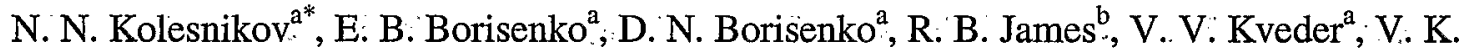 \\ Gärtman ${ }^{\mathrm{a}}$, and B. A. Gnesin ${ }^{\mathrm{a}}$ \\ ${ }^{a}$ Institute of Solid State Physics, the Russian Academy of Sciences, Chernogolovka,'Moscow distr.,', . \\ 142432 Russia \\ ${ }^{\mathrm{b}}$ Brookhaven National.Laboratory; Upton, NY 11973-5000 USA
}

\begin{abstract}
. .
Wide-gap II-VI semiconductor crystalline materials are conventionally used in laser optics, light emitting. devices, and nuclear detectors. The advances made in the studies of nanocrystals and in the associated technologies have created great interest in the design of semiconductor devices based on these new materials.

The objectives of this work are to study the microstructure and the properties of the new.material produced through CdTe nanopowder compression and to consider the prospects of its use in the design of ionizing-radiation detectors and. in laser optics.

Highly dense material produced of 7-10 $\mathrm{nm}$ CdTe particles under pressure of 20-600 MPa at temperatures from 20 to $\cdots$ $200^{\circ} \mathrm{C}$ was analyzed using $\mathrm{x}$-ray diffractometry, texture analysis, jight and scanning electron microscopy, and optical : spectrophotometry. The mechanical and electrical properties of the compacted material were measured and compared with similar characteristics of the conventionally grown single crystals. Phase transformation from metastable to stable :. crystal structure caused by deformation was observed in the material. Sharp crystallographic texture $\{001\}<\mathrm{hk} 0>$ that apparently affects specific mechanical, electrical and optical characteristics of compacted CdTe was observed.

The specific resistivity calculated from the linear current-voltage characteristics was about $10^{10} . \mathrm{Ohm} \times \mathrm{cm}$; which is a promisingly high value regarding the possibility of using this material in the design of semiconductor radiation detectors. The optical spectra show that the transmittance in the infrared region is sufficient to consider the prospects of possible applications of CdTe ceramics in laser optics.
\end{abstract}

Keywords: Nanotechnology, semiconductor $\mathrm{A}^{\mathrm{II}} \mathrm{B}^{\mathrm{VI}}$ materials; recrystallization, phase transitions

\section{INTRODUCTION}

The recent developments of nanotechnologies open the possibilities of using the materials in laser optics and semiconductor detector applications.

We have already reported the method of nanocrystalline CdTe growth based on the vapor condensation of the evaporated bulk crystal carried out in a helium gas flow. ${ }^{1}$. The deposited powder consisted of nanoparticles of $7-10 \mathrm{~nm}$ in diameter. The present studies are aimed at fabrication of a bulk material from this powder and at studying the structural; electrical; optical and mechanical properties of these materials with the prospect of using them in the design of semiconductor $;. .$. radiation detectors and in infrared laser optics.

\section{EXPERIMENTAL}

The compacted CdTe material was produced from the nanopowder, which consisted of particles of 7-10 nm in diameter deposited from the vapor phase using the technique described in Ref..1.

$\mathrm{CdTe}$ was compacted using a one-die scheme in Instron machine under a pressure in the range from 20 to $600 \mathrm{MPa}$. The temperature of compression varied in the range of $20-200^{\circ} \mathrm{C}$. After the required pressure had been achieved, the specimen: was kept under pressure for 0.5-120 min. The chosen lower temperature-range limit of compression ensured

\footnotetext{
* Institute of Solid State Physics Russian Acad. Sci., Chernogolovka, Moscow Distr., 142432 Russia. Tel: +7-096-522-

2074, Fax: +7-096-522-4691, http://www.sttic.com.ru/lpcbc/lpcbc.html, E-mail: nkolesn@issp.ac.ru
} 
the most convenient and economical experimental scheme to obtain rather dense material. The increase in the compression temperature was limited by the tendency of II-VI compounds to oxidize and partially decompose above $300^{\circ} \mathrm{C}^{2}$.

$\mathrm{X}$-ray phase analysis was carried out using a Siemens D400 diffractomer. A specimen was fixed in the ring-shaped holder with a $2-\mathrm{mm}$ accuracy of alignment. The angle step was $0.05^{\circ}$, and the exposition time was $20 \mathrm{~s}$ for each point. $\mathrm{FeK}_{\alpha}$ radiation was used.

The crystal texture of the compacted samples was studied using a reflection.(Schultz) technique. The tilt-angle range was $0-50^{\circ}$, the azimuth and the polar angle steps were $5^{\circ}$; and the exposition time in each point was. 3 s. The background and defocusing effect were taken into account when the experimental data on detected pulses were processed. To obtain a pole figure ( $\mathrm{PF}$ ); the X-ray detector was.set in a certain position based on the angle distance of the strongest lines detected in the previously recorded diffractograms of the compacted CdTe. Level curves in PFs show a current-to-maximum intensity ratio.

Microhardness was measured using the standard Vickers technique. The load was $100 \mathrm{~g}$.

The light-transmittance spectra were recorded within the wavelength range of 2.5-25 $\mu \mathrm{m}$ using a spectrophotometer Specord $75 \cdot \mathbb{R}$.

The specific resistivity was measured using the four-point-probe direct current technique. Gold films of $2.5-\mu \mathrm{m}$ thickness were deposited on the sample surfaces in vacuum. The current-voltage characteristics (CVC) were obtained using a bias voltage source produced by Ortec...

\section{RESULTS AND DISCUSSION}

The density of CdTe, compacted at room temperature under pressure 60-600 Mpa, was measured using hydrostatic weighting, and the value was found to be $93-97 \%$ of the single crystal density. The accuracy of the measurements was 2 $\%$. The porosity of the specimens measured by a standard metallographic technique was about $5 \%$. Consequently, we regarded the compacted CdTe as a bulk material in our further studies. A single CdTe crystal grown using high-pressure vertical zone melting (HPVZM) technique ${ }^{2}$ was used for comparison.

Diffractograms in Fig. 1 (a, b) show the changes in phase content of CdTe powder subjected to compression. According to the diffractograms, the powder initially consists of the metastable hexagonal phase with wurtzite structure and gradually converts into the stable cubic sphalerite structure as the applied pressure increases.
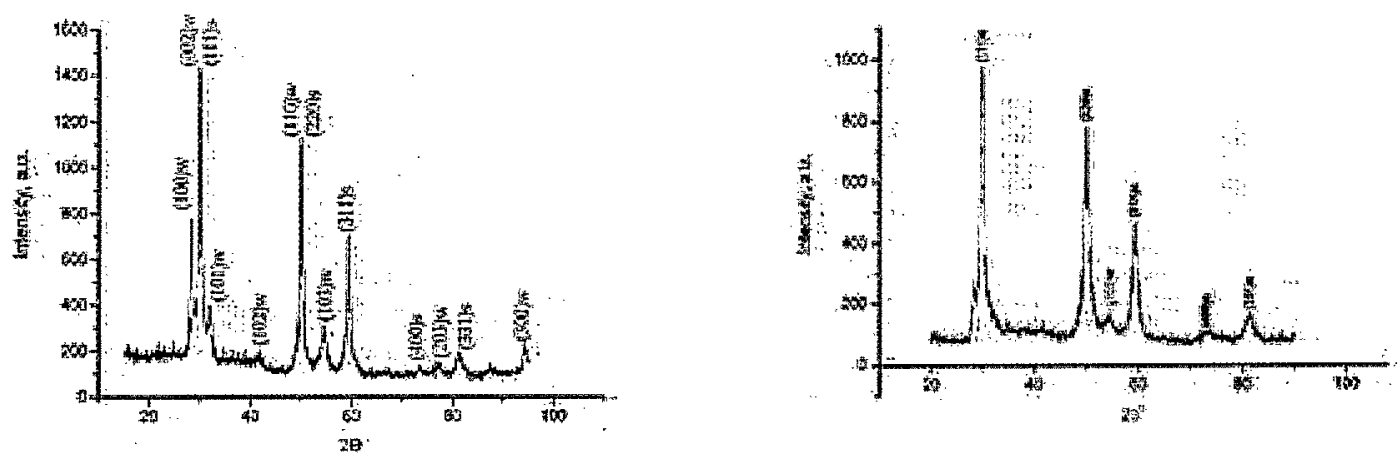

Figure 1: Diffractogram of:(a) CdTe nanopowder, (b) of CdTe compacted at $20^{\circ} \mathrm{C}$ under pressure $\mathrm{p}=600 \mathrm{Mpa}$. Here, $w$ is for wurtzite; and $s$ is for sphalerite structure.

The microstructure of compacted CdTe was revealed by etching in a solution that contained $7 \mathrm{vol} . \%$ bromine and 93 vol: \% methanol. It was observed that the structure consisted of grains elongated along a certain crystalline direction (Fig. 2). The mean size of grains in the CdTe compacted at $600 \mathrm{MPa}$ at room temperature was about $8 \mu \mathrm{m}$. An increase in the temperature of compression and time under pressure caused grain growth. For example, in the sample compressed at a temperature of $200^{\circ} \mathrm{C}$ for an hour, the grain size was about $60 \mu \mathrm{m}$. These results are consistent with the fact that the 
line widths in the diffractograms:were narrower with increases in compression temperature and time:. At the same time, the growing grains became more equiaxed:

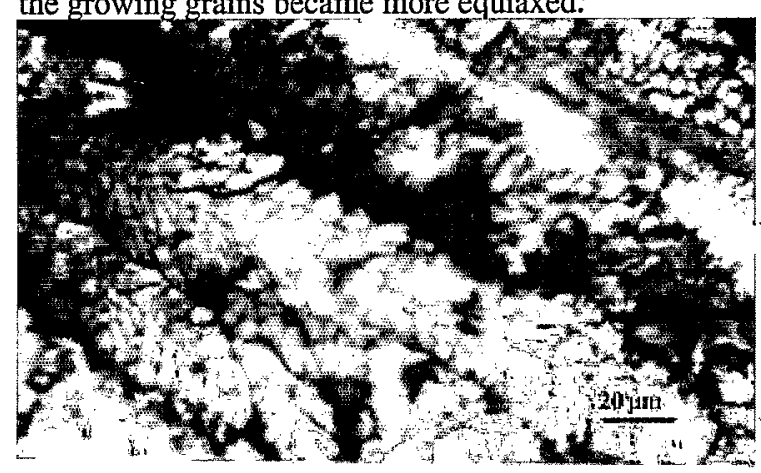

Figure 2: Microstructure of CdTe compressed at the temperature $20^{\circ} \mathrm{C}$ under pressure $\mathrm{p}=600 \mathrm{MPa}$.

If we look at the $\{220\}$ pole figures (PF) detected at different temperatures (Fig. 3a, b), we can see that the higher the : compression temperature, the more scattered is the texture. This corresponds well with the results on grain growth obtained by light microscopy: Furthermore, it should be noted that; while the axial texture $\langle 220\rangle$ that we observe.in the compacted CdTe could have been predicted; the surprisingly sharp $\{001\}<\mathrm{hk} 0>$ component is unusual for a material fabricated by powder compression. Anyway, based on the PF observations, we can explain the effect that the structure has on some properties of the compacted CdTe.
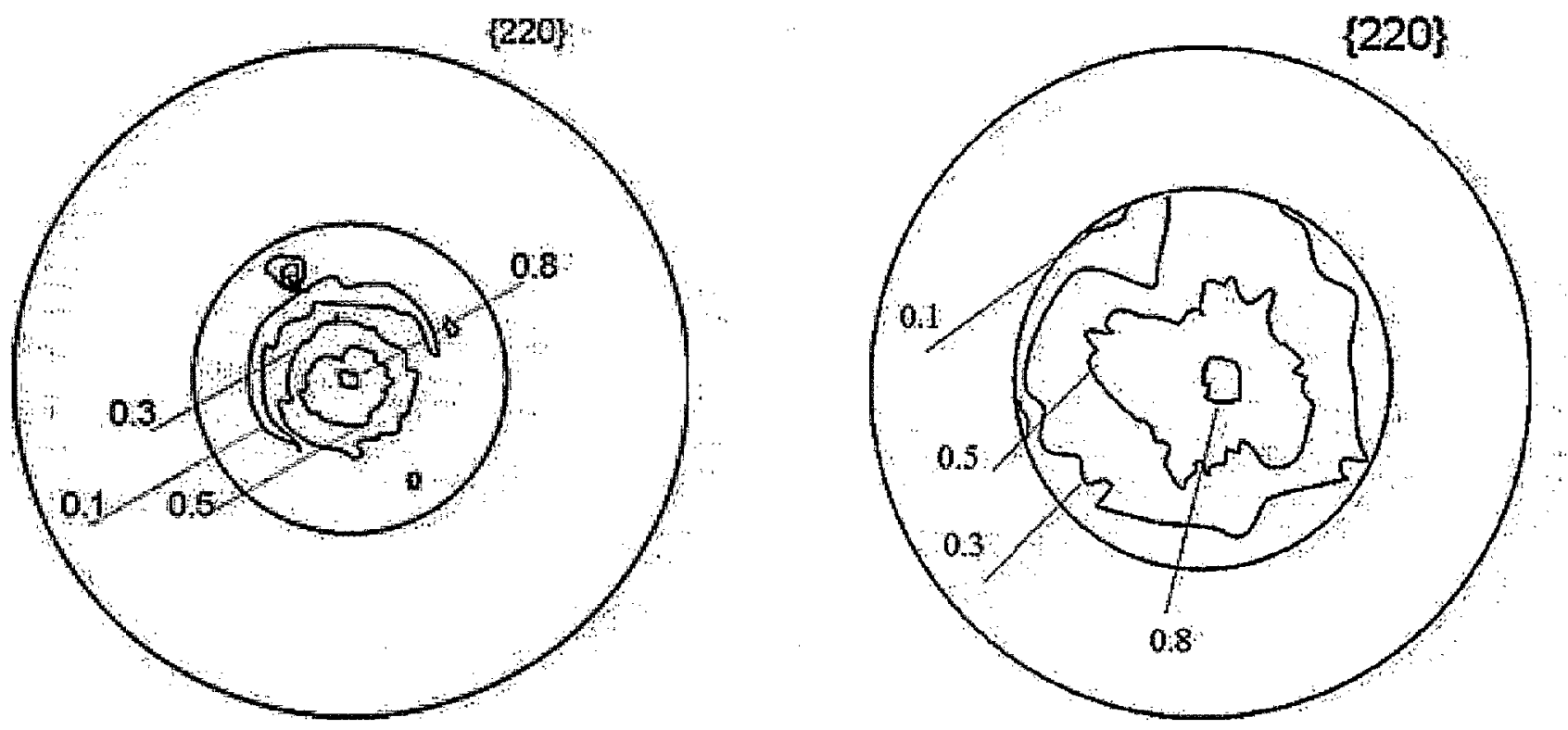

Figure 3: Pole figure $\{220\}$ of compacted CdTe fabricated (a) at the temperature $20^{\circ} \mathrm{C}$ under pressure $\mathrm{p}=600 \mathrm{MPa}$; (b) at the temperature $200^{\circ} \mathrm{C}$ under pressure $p=600 \mathrm{MPa}$.

For example, the microhardness of the compacted specimens (curve 1 of Fig. 4) is $1450 \mathrm{MPa}$, which is more than three. times higher than the microhardness of a single crystal grown from melt: In the same figure (curve 2), it can be seen that rise in temperature causes a decrease in the microhardness. These results along with the observed variations of microstructure and crystallographic orientation with temperature give evidence that dynamic recrystallization takes place under compression of CdTe. However, despite the reduction in the concentration of defects, which is most probably 
caused by grain growth, microhardness. still remains rather high at the elevated compression temperature. This might be due to pores healing with temperature (by $3-4 . \%$ ), which is confirmed by metallographic studies.

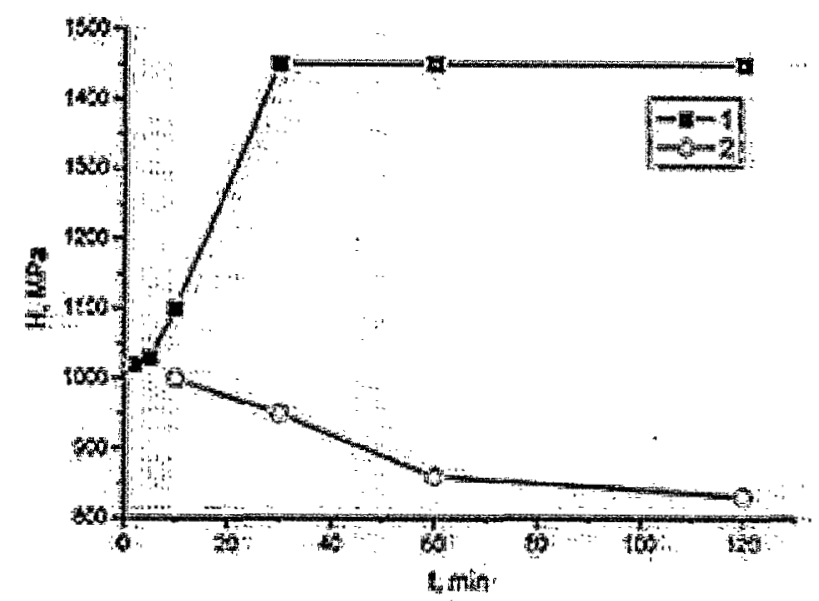

Figure 4: Time function of microhardness of CdTe ceramics fabricated at $20^{\circ} \mathrm{C}(1)$ and $200^{\circ} \mathrm{C}(2)$.

Another characteristic that we studied was electrical resistivity. This characteristic is very important in CdTe aimed for application as a detector of ionizing radiation. The almost linear current-voltage characteristics (CVC) with very small hysteresis confirm that with the contacts are ohmic. The electrical resistivity values of CdTe ceramics (approximately $10^{10} \Omega \cdot \mathrm{cm}$ ) are more than an order of magnitude higher than respective values of CdTe single crystals (approximately $2: 10^{8} \Omega \cdot \mathrm{cm}$ ) (Fig. 5).

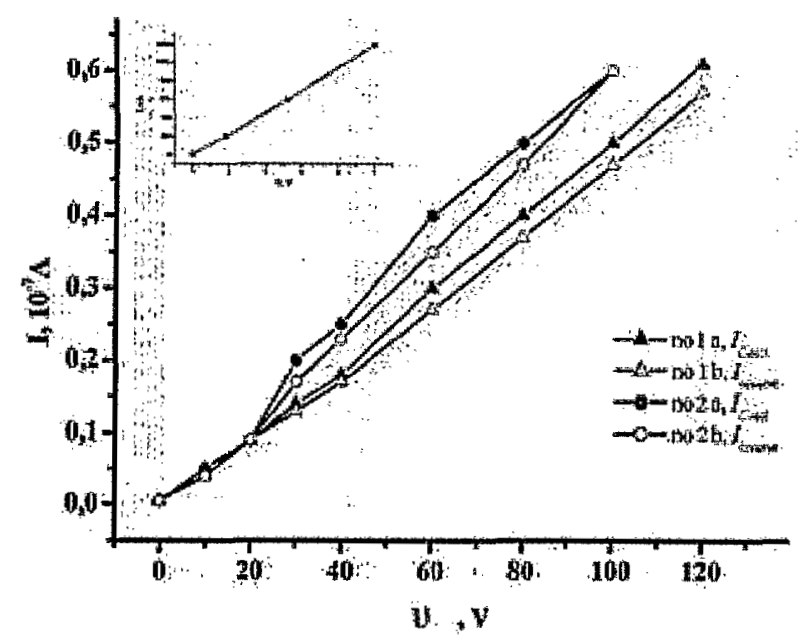

Figure 5: The current-voltage characteristics of compacted CdTe, CVC of a single CdTe crystal is shown in the inset; indices $I$ direct. and $I_{\text {reverse }}$ are for direct and reverse current respectively. These samples were compressed under pressure $\mathrm{p}=600 \mathrm{MPa}$ at the temperature of $20^{\circ} \mathrm{C}$ during $30 \mathrm{~min}(1)$ and $10 \mathrm{~min}$ (2).

The transmittance spectrum of the compacted CdTe (curve 1 of Fig. 6) shows that the transmittance in the infrared region is relatively high, though lower than in a single crystal (curve 2 of Fig. 6). The low transmittance in the wavelength 
region of 4:5 $\mu \mathrm{m}$ is probably caused by scattering on grain boundaries rather than on pores, because the pore concentration of $3-5 \%$ is too low to be responsible for this effect. Here, we compare the spectra of a polished CdTe: single crystal and $\mathrm{CdTe}$ ceramics with a rough surface, because the correspondent polishing technique for compacted $\mathrm{CdTe}$ has not yet been developed. So, a lower transmittance might be due to light scattering on the rough surface.

However, the optical spectra show that the transmittance in the mid-IR region is.high enough for CdTe ceramics to be regarded as a promising material for laser optics. 'The transmittance spectrum also confirms indirectly that the CdTe ceramics under investigation have high specific resistivity: A spectrum of low-resistivity CdTe is shown in Fig. 6 (curve 3) for comparison.

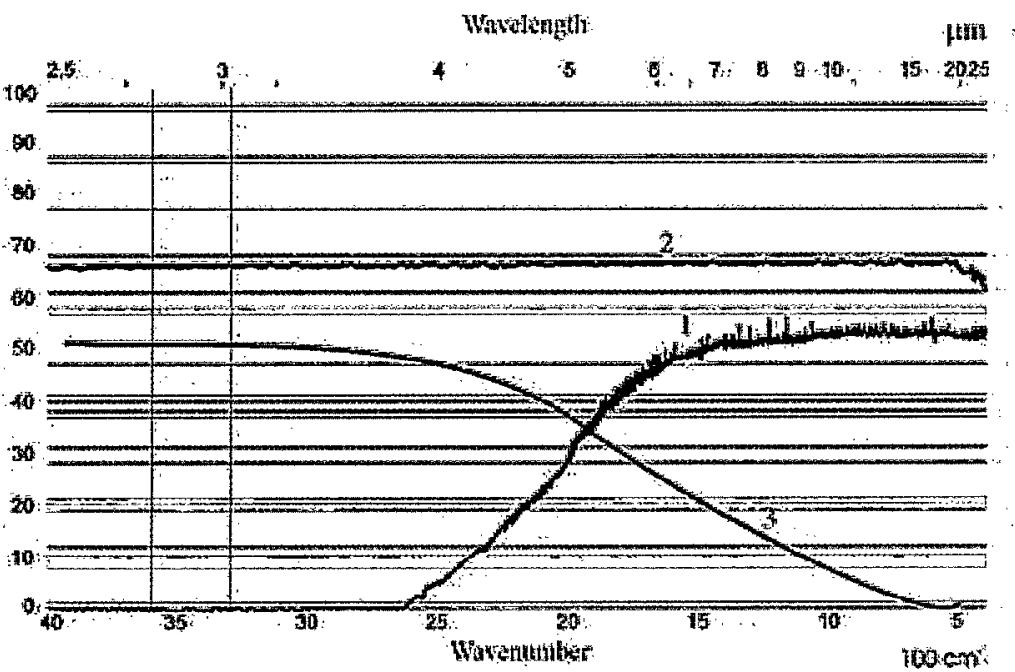

Figure 6: The transmittance spectra of CdTe (1) ceramics, (2) single crystal with high specific resistivity; and (3) single crystal with low specific resistivity.

\section{CONCLUSIONS}

1. Using low-temperature compaction of nanopowder, high-density CdTe ceramics were fabricated:

2. A pressure-induced phase transformation from metastable hexagonal to stable cubic structure was observed

3.. Variations in microstructure and crystallographic texture of compacted CdTe show the presence of dynamic recrystallization under compression.

4. The measured specific resistivity of compacted CdTe is approximately $10^{10} \mathrm{Ohm} \cdot \mathrm{cm}$, which is a promisingly high value suggesting the possibility of using this material in the design of $X$ - and gamma detectors.

5. A relatively high transmittance in infrared region indicates the prospects of using CdTe ceramics in infrared optics.

\section{REFERENCES}

1. 1. N: N. Kolesnikov, V. V. Kveder, R. B. James, D. N. Borisenko, and M. P. Kulakov, Nucl. Instr. and Meth. in Phys. Research A527 (2004) 73;

2. N: N. Kolesnikov; R. B. James, N: S. Berzigiarova, and M. P. Kulakov, Proceedings of SPIE: X-Ray and GammaRay. Detectors and Applications. IV, Editors: R. B. James, L. A. Franks, A. Burger,: E. M. Westbrook, and R. D. Durst, Vol. 4784 (2002) 93. 